\title{
Ivermectin treatment for Strongyloides infection in patients with COVID-19
}

\author{
Elizabeth Leung ${ }^{1,2,3 *}$, Sumit Raybardhan ${ }^{3,4}$, Christopher Graham ${ }^{3,5}$, Caroline Nott ${ }^{3,6}$, \\ Bradley J Langford ${ }^{3,7}$, Nisha Andany ${ }^{3,8,9}$, William Ciccotelli, ${ }^{3,10,11}$, Sumon Chakrabarti, \\ Isaac I Bogoch9, Wayne L Gold ${ }^{3,9,12}$, Menaka Pai3 ${ }^{3,13,14,15}$, Andrew M Morris ${ }^{3,9,15,16}$, Anne McCarthy ${ }^{17}$
}

\begin{abstract}
Ivermectin, an antiparasitic agent, is not recommended for prophylaxis or treatment of coronavirus disease 2019 (COVID-19). Inappropriate use of ivermectin for treatment of COVID-19 may make it less available for patients with serious parasitic infections who could benefit from its use and worsen the current shortage of ivermectin in Canada. However, patients with COVID-19 who are candidates to receive immunomodulatory therapies (e.g. corticosteroids and interleukin-6 inhibitors) may be at risk of hyperinfection syndrome and disseminated disease from Strongyloides stercoralis. These complications can be severe and even fatal. It is important to recognize and screen patients who may be at risk of strongyloidiasis, as these patients may require treatment with ivermectin to avoid the potential for a hyperinfection syndrome and disseminated disease, which is frequently deadly. Clinicians should follow evidence-based recommendations to screen and treat for Strongyloides infection in patients with COVID-19 who are under consideration to receive specific COVID-19 therapies that alter immune response and may lead to hyperinfection syndrome or disseminated disease.
\end{abstract}

Suggested citation: Leung E, Raybardhan S, Graham C, Nott C, Langford BJ, Andany N, Ciccotelli W, Chakrabarti S, Bogoch II, Gold WL, Pai M, Morris AM, McCarthy A. Ivermectin treatment for Strongyloides infection in patients with COVID-19. Can Commun Dis Rep 2021;47(7/8):316-21.

https://doi.org/10.14745/ccdr.v47i78a04

Keywords: COVID-19, Strongyloides, ivermectin, immunosuppression, corticosteroids, IL-6 inhibitors, strongyloidiasis

\section{Introduction}

Ivermectin is an oral drug approved in Canada for the treatment of certain parasitic infections (e.g. strongyloidiasis and onchocerciasis) (1). In vitro data have demonstrated that ivermectin has antiviral activity against severe acute respiratory syndrome coronavirus 2 (SARS-CoV-2) and can prevent viral proteins from binding to and entering cells (2). This has contributed to the view that ivermectin may have antiviral effects in vivo. However, the plasma concentrations that are required to achieve antiviral effect are significantly higher than the maximum achievable plasma concentrations with tolerable doses in humans (3). Ivermectin is currently not recommended for prophylaxis or treatment of coronavirus disease 2019 (COVID-19) (4), as current evidence does not show clinical benefit (5). In the absence of evidence showing a clinical benefit for ivermectin in the treatment of COVID-19, there are compelling reasons to conserve limited national and provincial supplies of ivermectin by only using it for evidence-based indications.

It is important to note that the primary and approved use of ivermectin is as an antiparasitic agent. One parasite of interest is Strongyloides stercoralis. Strongyloides infection ranges in presentation from asymptomatic intestinal infection to hyperinfection and severe disseminated disease. Patients with chronic asymptomatic $S$. stercoralis infection and impaired immunity may develop "accelerated
This work is licensed under a Creative Commons Attribution 4.0 International License.

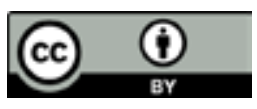

Affiliations

1 Department of Pharmacy, St. Michael's Hospital/Unity Health Toronto, Toronto, ON

2 Leslie Dan Faculty of Pharmacy, University of Toronto, Toronto, ON

${ }^{3}$ Ontario COVID-19 Science Advisory Table Drugs and Biologics Clinical

Practice Guidelines Working Group

${ }^{4}$ Department of Pharmacy, North York General Hospital, Toronto, ON

5 Trillium Health Partners,

Mississauga, ON

${ }^{6}$ Department of Medicine, University of Ottawa, Ottawa, ON

7 Public Health Ontario, Toronto, ON

${ }^{8}$ Division of Infectious Diseases,

Sunnybrook Health Sciences Centre,

Toronto, ON

9 Department of Medicine, University of Toronto, Toronto, ON

${ }^{10}$ Grand River Hospital, Kitchener, ON

${ }^{11}$ St. Mary's General Hospital, Kitchener, ON

12 Department of Medicine, University Health Network, Toronto, ON

${ }^{13}$ McMaster University, Hamilton, ON

${ }^{14}$ Hamilton Health Sciences and Hamilton Regional Laboratory Medicine Program, Hamilton, ON

${ }^{15}$ Ontario COVID-19 Science Advisory Table

${ }^{16}$ Department of Medicine, Sinai Health and University Health Network, Toronto, ON

${ }^{17}$ Division of Infectious Diseases, The Ottawa Hospital, Ottawa, ON

\section{*Correspondence:}

beth.leung@utoronto.ca 
auto-infection", known as hyperinfection. These patients may also experience disseminated disease secondary to larval migration outside their usual anatomic reservoir, with varying presentations (e.g. pneumonia, central nervous system infection, recurrent gram-negative or polymicrobial bacteremia and sepsis). Immunosuppression, in particular corticosteroid use, has been associated with increased risk of hyperinfection syndrome in patients with chronic Strongyloides infection.

Clinicians can refer to the Ontario Science Advisory Table Science Brief "Ivermectin as Empiric Treatment for Strongyloides in Patients with COVID-19 Disease" for full details to further support the recommendations submitted in this article. The Science Table full brief is available online.

\section{Current situation}

In patients with strongyloidiasis (including asymptomatic Strongyloides infection), immunosuppression can lead to a worsening of the parasitic infection including hyperinfection and disseminated disease, which is a devastating illness with mortality rates approaching $90 \%$ if left untreated $(6,7)$. Although most reports of hyperinfection syndrome implicate corticosteroids as the main risk factor, there are also reports with other immunosuppressive or immunomodulatory agents including tumour necrosis factor (TNF), interleukin-1 (IL-1) and other non-steroid lymphocyte depleting agents $(6,7)$. A recent European Society of Clinical Microbiology and Infectious Diseases review on the safety of biological therapies did not identify Strongyloides as a major infectious risk with IL-6 inhibitors (including tocilizumab) (8). However, there have been case reports of Strongyloides hyperinfection developing in patients who received concomitant corticosteroid therapy with tocilizumab (9-11).

Dexamethasone and tocilizumab, two evidence-based therapies for the treatment of moderately and critically-ill patients with COVID-19, are both anti-inflammatory agents with immunosuppressive effects. There is no clear relationship between a threshold dose and duration of immunosuppression at which the risk of disseminated Strongyloides infection may occur. It is also currently not well described how concomitant immunosuppressive medications may interact to affect hyperinfection risk, or whether those who receive multiple immunosuppressive therapies are at additional risk for disseminated disease.

\section{Current limited supply of ivermectin}

Ivermectin is an essential medication for treatment of strongyloidiasis (and is an important component of combination therapy for hyperinfection syndrome and fulminant, disseminated disease). As of January 21, 2021, ivermectin has been listed on shortage by Drug Shortages Canada, with only limited quantities available due to increased demand for the drug; the estimated shortage end date is December 31, 2021, which is subject to change based on supply and demand (12). Therefore, clinicians are currently encouraged to use ivermectin only when necessary for evidence-based clinical indications, and may need to be prepared to consider using substitute agents if ivermectin becomes locally unavailable. In this brief review, we discuss the application of existing Strongyloides screening recommendations to patients with COVID-19, and suggested Strongyloides treatment strategies to preserve ivermectin supply while ensuring appropriate treatment for patients with COVID-19 at risk for hyperinfection (see Appendix Table A1).

\section{Assessment of Strongyloides risk in patients with COVID-19}

The rate of Strongyloides infection in Canada is not well described, but the Committee to Advise on Tropical Medicine and Travel (CATMAT) estimates that as many as 2.5 million individuals in Canada have simple intestinal strongyloidiasis (assuming a prevalence rate of $40 \%$ in the patient country of origin, although seroprevalence has been noted to be above $60 \%$ among immigrants from endemic regions). In 2016, CATMAT noted that almost seven million Canadians were foreign-born, and $85 \%$ of this population were from a country where $S$. stercoralis is endemic; therefore, the risk of strongyloidiasis in Canada is not negligible (6).

For patients with COVID-19 who are under consideration to receive immunosuppressive therapy, the first step is to assess their risk for progressing to severe strongyloidiasis based on both epidemiologic and clinical factors. We recommend following the CATMAT guidelines Step 1-epidemiologic assessment (based on country of prior residence or extended exposure) $(6,13)$. Of note, the CATMAT guidelines outline risk related to a corticosteroid dose "equivalent to $20 \mathrm{mg} /$ day of prednisone for $\geq 2$ weeks", and we assume that the dose of corticosteroid recommended for COVID-19 treatment is similar to this relatively arbitrary cutoff. Hyperinfection syndrome has been reported with a range of corticosteroid doses and durations, and it is still unknown whether concomitant immunosuppressive therapies contribute to a higher relative risk of hyperinfection.

We also recognize that geographic epidemiologic risk alone may place many patients in the moderate risk category (if not the high risk category), and this may also overlap with patient demographics in neighbourhoods and communities which have been highly and disproportionately impacted by the COVID-19 pandemic (14).

We also recommend following CATMAT guidelines Step 2assessment of clinical risk and suspected clinical syndrome. This Step will identify what diagnostic tests should be done to screen for strongyloidiasis. Ideally, S. stercoralis testing is performed 
prior to administration of immunosuppressive therapy, but often this is not possible in patients with COVID-19. Patients at moderate or high epidemiologic risk of Strongyloides infection should proceed to serologic testing as soon as possible (even if immunosuppression has already been initiated), while patients at low epidemiologic risk of Strongyloides infection do not require diagnostic screening unless there is clinical suspicion of Strongyloides hyperinfection or dissemination. Clinicians should note that any patients who have clinical signs/symptoms of active strongyloidiasis, hyperinfection or dissemination will require additional diagnostic testing, empiric treatment, and expert consultation (6).

\section{Treatment of strongyloidiasis in patients with COVID-19}

Ivermectin dosing for treatment of strongyloidiasis differs depending on the clinical syndrome. Less severe forms of strongyloidiasis (e.g. mild intestinal or asymptomatic strongyloidiasis) are now mostly treated with a single weightbased dose of ivermectin ( $200 \mu \mathrm{g}$ per kilogram), based on emerging evidence that a single dose is as effective as multiple doses (15). Clinicians may consider repeating serology after a single dose regimen if treatment failure is suspected. When a two-dose regimen of ivermectin is used, the doses are typically administered on consecutive days or separated by 14 days. When a two-dose regimen is administered, the separateddose regimen is preferred to consecutive doses due to the risk of prepatent infection arising from auto-infection although consecutive doses may be used if medication adherence is a concern (e.g. healthcare system challenges related to increased frequency of intra and inter-hospital patient transfers during the COVID-19 pandemic). Severe forms of strongyloidiasis (e.g. hyperinfection and disseminated Strongyloides infection) often require daily weight-based dosing of ivermectin, sometimes given in combination with other antihelminthic agents such as albendazole (6).

We recommend following CATMAT guidelines Step 3 to decide whether a patient should be screened and/or treated with ivermectin for strongyloidiasis. This approach takes into account both the epidemiologic (Step 1) and clinical risks (Step 2) assessments. Most patients with an epidemiologic risk for Strongyloides infection, and for whom immunomodulatory therapies (either dexamethasone, tocilizumab, or both) are being considered during their hospitalization for COVID-19, are at risk for asymptomatic strongyloidiasis. As outlined earlier, many of these patients may also meet the "high" or "moderate" category of geographic epidemiologic risk. In these cases, it is important that clinicians send the appropriate specimens for diagnostic testing and also monitor the patient after receipt of immunomodulatory therapy for any signs/symptoms of Strongyloides infection which could potentially progress to hyperinfection syndrome and disseminated disease if not treated promptly.
The CATMAT guidelines (prior to COVID-19) indicate that empiric treatment with two doses of ivermectin may be given "in the rare circumstance where the patient is deemed high risk for strongyloidiasis and immunosuppression cannot await definitive diagnostic testing" (6). However, given the current limited national supply of ivermectin, we recommend waiting for Strongyloides serology results (if results can be obtained reasonably quickly-e.g. within 24 hours) before initiating ivermectin for treatment of asymptomatic strongyloidiasis. Patients with a reactive or indeterminate Strongyloides serology result should be treated for asymptomatic strongyloidiasis as described earlier. If laboratory results cannot be expedited, it is reasonable to wait for serology results if the patient is clinically stable and only administer empiric ivermectin therapy if the patient is clinically unstable. If there is suspicion for hyperinfection at the time of COVID-19 presentation, infectious disease specialist consultation is recommended.

Finally, an important consideration before any ivermectin therapy is initiated, is screening for the presence of concurrent loiasis (infection with the filarial nematode Loa loa), due to the risk of severe reactions, including fatal encephalopathy, if ivermectin is administered to a patient with untreated loiasis. Clinicians should consult with an infectious diseases/tropical medicine expert for recommendations on Strongyloides treatment in patients who are from Loa loa endemic areas; namely West and Central Africa $(6,16)$. Recommended testing includes a daytime blood film examination for Loa loa microfilaria.

\section{Serologic testing expected turn-around-time}

In the absence of immunosuppression, screening for Strongyloides by microscopic examination of stool or sputum for ova and parasites (OAP) may only produce a positive result if the patient has a high burden of infection (e.g. if the patient is symptomatic or already experiencing hyperinfection syndrome). Therefore, although CATMAT guidelines recommend screening with both serology and stool OAP, we do not recommend sending stool OAP to screen for asymptomatic strongyloidiasisespecially given increased healthcare resource demands during the COVID-19 pandemic. Therefore, the ideal test to screen for Strongyloides (including asymptomatic infection) is a serologic test (17). S. stercoralis IgG serology testing is available through provincial laboratories and the turnaround time for results can be up to 10 days from receipt of blood sample by the laboratory (18). In situations where serology results will impact urgent treatment decisions, laboratories may be able to expedite serology test results. For example, in the most recent third wave of Ontario infections, the Public Health Ontario Laboratory has provided expedited Strongyloides serology testing results within 24 hours from receipt by the laboratory, for specimens marked as coming from a patient with COVID-19. A coordinated laboratory strategy can help to preserve limited ivermectin supplies while ensuring that patients at high risk of progression to hyperinfection are identified rapidly. 


\section{Conclusion}

COVID-19 mild illness: In patients who have mild COVID-19 there is currently insufficient evidence to support the use of immunomodulatory therapies (dexamethasone and tocilizumab). If patients who are mildly ill are to receive immunomodulatory therapy for COVID-19 or for other established non-COVID-19 indications, clinicians may use the CATMAT guidance recommendations to guide screening and/or treatment decisions.

COVID-19 moderate illness and critical illness: Patients who have moderate or critical COVID-19 are likely to be candidates to receive immunomodulatory therapies for treatment of COVID-19, and should therefore be screened for Strongyloides exposure/infection and may require treatment with ivermectin based on geographic epidemiologic risk and suspected Strongyloides clinical syndrome (Appendix Table A1).

\section{Authors' statement}

$E L$ - Wrote the first draft of the Science Brief $E L, S R, B J L, C G, N A, A M M$, and MP - Contributed to the conception of the Science Brief

All authors revised it critically for important intellectual content and approved the final version.

The content and view expressed in this article are those of the authors and do not necessarily reflect those of the Government of Canada.

\section{Competing interests}

None.

\section{Acknowledgements}

The Ontario COVID-19 Science Advisory Table is a group of scientific experts and health system leaders who evaluate and report on emerging evidence relevant to the COVID-19 pandemic, to inform Ontario's response. The mandate of the Science Advisory Table is to provide weekly summaries of relevant scientific evidence for the COVID-19 Health Coordination Table of the Province of Ontario, integrating information from existing scientific tables, Ontario's universities and agencies, and the best global evidence. The Science Table summarizes its findings for the Health Coordination Table and the public in Science Briefs.

The Drugs \& Biologics Clinical Practice Guidelines Working Group is a group of clinicians and scientists with recognized expertise in drugs, biologics and clinical care. The Working Group evaluates existing scientific data, disease epidemiology, drug availability and implementation issues in order to develop Clinical Practice Guidelines for the treatment of COVID-19 using drugs and biologics. The Working Group reports its findings to the public and the Science Table. Its findings are also summarized in Science Briefs.

The authors would like to acknowledge P Juni, M Mclntyre, $S$ Patel, and N Stall for their contributions to the Ontario Science Advisory Table Science Brief, "Ivermectin as Empiric Treatment for Strongyloides in Patients with COVID-19 Disease".

The authors thank M Deilgat and P Huston for their helpful comments and correspondence regarding this manuscript, given the urgent nature of this topic as related to the increasing COVID-19 case numbers across Canada.

\section{Funding}

None.

\section{References}

1. Merck Canada. Product Monograph. Stromectol. Ivermectin tablet. 2020. https://www.merck.ca/static/pdf/ STROMECTOL-PM_E.pdf

2. Caly L, Druce JD, Catton MG, Jans DA, Wagstaff KM. The FDA-approved drug ivermectin inhibits the replication of SARS-CoV-2 in vitro. Antiviral Res 2020;178:104787. DOI PubMed

3. Chaccour C, Hammann F, Ramón-García S, Rabinovich NR. Ivermectin and COVID-19: Keeping Rigor in Times of Urgency. Am J Trop Med Hyg 2020;102(6):1156-7. DOl PubMed

4. Clinical Practice Guideline Summary. Recommended Drugs and Biologics in Adult Patients with COVID-19. https:// covid19-sciencetable.ca/sciencebrief/clinical-practiceguideline-summary-recommended-drugs-and-biologics-inadult-patients-with-covid-19-version-2-0/

5. Siemieniuk RA, Bartoszko JJ, Ge L, Zeraatkar D, Izcovich A, Kum E, Pardo-Hernandez $H$, Rochwerg B, Lamontagne $F$, Han MA, Liu Q, Agarwal A, Agoritsas T, Chu DK, Couban R, Darzi A, Devji T, Fang B, Fang C, Flottorp SA, Foroutan F, Ghadimi M, Heels-Ansdell D, Honarmand K, Hou L, Hou X, Ibrahim Q, Khamis A, Lam B, Loeb M, Marcucci M, McLeod SL, Motaghi S, Murthy S, Mustafa RA, Neary JD, Qasim A, Rada G, Riaz IB, Sadeghirad B, Sekercioglu N, Sheng L, Sreekanta A, Switzer C, Tendal B, Thabane L, Tomlinson G, Turner T, Vandvik PO, Vernooij RW Viteri-García A, Wang Y, Yao L, Ye Z, Guyatt GH, Brignardello-Petersen R, Qasim A, Martinez JP, Cusano E. Drug treatments for covid-19: living systematic review and network meta-analysis. BMJ 2020;370:m2980. DOI PubMed 
6. Boggild AK, Libman M, Greenaway C, McCarthy AE; Committee to Advise on Tropical Medicine; Travel (CATMAT). CATMAT statement on disseminated strongyloidiasis: Prevention, assessment and management guidelines. Can Commun Dis Rep 2016;42(1):12-9.

DOI PubMed

7. Stauffer WM, Alpern JD, Walker PF. COVID-19 and Dexamethasone: A Potential Strategy to Avoid Steroid-Related Strongyloides Hyperinfection. JAMA 2020;324(7):623-4. DOl PubMed

8. Winthrop KL, Mariette X, Silva JT, Benamu E, Calabrese LH, Dumusc A, Smolen JS, Aguado JM, Fernández-Ruiz M. ESCMID Study Group for Infections in Compromised Hosts (ESGICH) Consensus Document on the safety of targeted and biological therapies: an infectious diseases perspective (Soluble immune effector molecules [II]: agents targeting interleukins, immunoglobulins and complement factors). Clin Microbiol Infect 2018;24 Suppl 2:S21-40. DOI PubMed

9. Lier AJ, Tuan JJ, Davis MW, Paulson N, McManus D, Campbell S, Peaper DR, Topal JE. Case report: disseminated strongyloidiasis in a patient with COVID-19. Am J Trop Med Hyg 2020;103(4):1590-2. DOI PubMed

10. Marchese V, Crosato V, Gulletta M, Castelnuovo F, Cristini G, Matteelli A, Castelli F. Strongyloides infection manifested during immunosuppressive therapy for SARS-CoV-2 pneumonia. Infection 2021;49(3):539-42. DOI PubMed

11. Mafort TT, Reis LV, Faria LF, Pinto BM, Silva RV, Miranda CS, Oliveira JG. Alveolar hemorrhage secondary to infection by Strongyloides stercoralis in immunosuppressed patientcase report. Am J Respir Crit Care Med. 2017;195:A5586 (conference abstract). https://www.atsjournals.org/ doi/abs/10.1164/ajrccm-conference.2017.195.1_ MeetingAbstracts.A5586

12. Health Canada. Drug Shortages Canada. Drug Shortage Report for Stromectol (updated 2021-04-27; accessed 2021-02-09). https://www.drugshortagescanada.ca/ shortage/131914
13. Buonfrate $D$, Bisanzio $D$, Giorli $G$, Odermatt $P$, Fürst $T$, Greenaway C, French M, Reithinger R, Gobbi F, Montresor A, Bisoffi Z. The Global Prevalence of Strongyloides stercoralis Infection. Pathogens 2020;9(6):E468. DOI PubMed

14. Brown KA, Stall NM, Joh E, Allen U, Bogoch II, Buchan SA, Daneman N, Evans GA, Fisman DN, Gibson JL, Hopkins J, Van Ingen T, Maltsev A, McGeer A, Mishra S, Razak F, Sander B, Schwartz B, Schwartz K, Siddiqi A, Smylie J. Jüni P on behalf of the Ontario COVID-19 Science Advisory Table. A Strategy for the Mass Distribution of COVID-19 Vaccines in Ontario Based on Age and Neighbourhood. Science Table - COVID-19 Advisory for Ontario; (updated 2020-09-23; accessed 2021-02-26). DOI

15. Buonfrate D, Salas-Coronas J, Muñoz J, Maruri BT, Rodari P, Castelli F, Zammarchi L, Bianchi L, Gobbi F, Cabezas-Fernández T, Requena-Mendez A, Godbole G, Silva R, Romero M, Chiodini PL, Bisoffi Z. Multiple-dose versus single-dose ivermectin for Strongyloides stercoralis infection (Strong Treat 1 to 4): a multicentre, open-label, phase 3 , randomised controlled superiority trial. Lancet Infect Dis 2019;19(11):1181-90. DOl PubMed

16. Centers for Disease Control and Prevention. Parasites Loaisis. Atlanta (GA): CDC; (updated 2015-01-20). https://www.cdc.gov/parasites/loiasis/index.html

17. Dong MD, Karsenti N, Lau R, Ralevski F, Cheema K, Burton L, Klowak M, Boggild AK. Strongyloidiasis in Ontario: performance of diagnostic tests over a 14-month period. Travel Med Infect Dis 2016;14(6):625-9. DOI PubMed

18. Public Health Ontario. Laboratory Services Test Information Index. Strongyloides Serology. PHO; (updated 2020-07-20). https://www.publichealthontario.ca/en/laboratory-services/ test-information-index/strongyloides-serology 


\section{Appendix: Therapeutic recommendations}

For therapeutic recommendations, we used the following definitions for COVID-19 severity:

Critically ill: Patients requiring ventilatory and/or circulatory support, including high-flow nasal oxygen, non-invasive ventilation, invasive mechanical ventilation or extracorporeal membrane oxygenation. These patients are usually managed in an intensive care setting.
Moderately ill: Patients newly requiring low-flow supplemental oxygen. These patients are usually managed in hospital wards.

Mildly ill: Patients who do not require new or additional supplemental oxygen from their baseline status, intravenous fluids, or other physiological support. These patients are usually managed in an ambulatory/outpatient setting.

Table A1: Recommendations for Strongyloides screening and treatment in patients who are candidates to receive immunomodulatory therapies for treatment of COVID-19 (moderately ill or critically ill)

\begin{tabular}{|c|c|c|c|}
\hline \multirow{3}{*}{$\begin{array}{l}\text { Geographic } \\
\text { epidemiologic } \\
\text { risk category for } \\
\text { Strongyloides } \\
\text { exposure/infection }\end{array}$} & \multicolumn{3}{|c|}{ Suspected clinical syndrome upon COVID-19 presentation ${ }^{a, b}$} \\
\hline & \multirow{2}{*}{$\begin{array}{l}\text { Asymptomatic strongyloidiasis } \\
+ \text { +/- eosinophiliac }\end{array}$} & $\begin{array}{l}\text { Simple intestinal } \\
\text { strongyloidiasis }\end{array}$ & $\begin{array}{l}\text { Hyperinfection syndrome } \\
\text { OR } \\
\text { disseminated strongyloidiasis }\end{array}$ \\
\hline & & \multicolumn{2}{|c|}{ Consult infectious diseases/tropical medicine specialist } \\
\hline $\begin{array}{l}\text { High risk }^{\text {d }} \\
\text { (birth or residence or } \\
\text { long-term travele in Sub- } \\
\text { Saharan Africa, South } \\
\text { America, Caribbean, } \\
\text { Southeast Asia, Oceania } \\
\text { excluding Australia/New } \\
\text { Zealand) }\end{array}$ & $\begin{array}{l}\text { Send serology } \\
\text { If an expedited serology result is } \\
\text { expected: } \\
\text { No empiric ivermectin therapy is required } \\
\text { (only treat if testing returns positive or } \\
\text { indeterminate) } \\
\text { If an expedited serology result is not } \\
\text { available: } \\
\text { If clinically stable, await results of serology } \\
\text { (only treat if testing returns positive or } \\
\text { indeterminate) } \\
\text { If clinically unstable, consider empiric } \\
\text { treatment while awaiting serology results } \\
\text { (ivermectin } 200 \mu \mathrm{g} / \mathrm{kg} \mathrm{PO} \times 1 \text { ) } \\
\text { If serology is positive or indeterminate and a } \\
2^{\text {nd }} \text { dose is given, space next dose at interval } \\
\text { of } 14 \text { days unless concern for adherence }\end{array}$ & $\begin{array}{l}\text { Send serology and stool OAP } \\
\text { Empiric treatment while } \\
\text { awaiting diagnostic testing } \\
\text { (ivermectin } 200 \mu \mathrm{g} / \mathrm{kg} \mathrm{PO} \times 1 \text { ) } \\
\text { If serology is positive or } \\
\text { indeterminate and a } 2^{\text {nd }} \text { dose } \\
\text { is given, space next dose } \\
\text { at interval of } 14 \text { days unless } \\
\text { concern for adherence }\end{array}$ & $\begin{array}{l}\text { Send serology }{ }^{\mathrm{h}} \text {, stool OAP, and sputum } \\
\text { OAP (+/- other bodily fluid or tissues for } \\
\text { examination for larvae) } \\
\text { Empiric treatment while awaiting results } \\
\text { (ivermectin } 200 \mu \mathrm{g} / \mathrm{kg} \text { PO q } 24 \mathrm{~h} \text { until } \\
\text { negative test results) } \\
\text { Consider addition of empiric } \\
\text { albendazole therapy }\end{array}$ \\
\hline $\begin{array}{l}\text { Moderate risk }{ }^{d} \\
\text { (birth or residence or } \\
\text { long-term travele in } \\
\text { Mediterranean countries, } \\
\text { Middle East, North Africa, } \\
\text { Indian sub-continent, Asia, } \\
\text { Central Americaf) }\end{array}$ & \multicolumn{2}{|c|}{$\begin{array}{l}\text { Send serology } \\
\text { No empiric ivermectin therapy is required (only treat if testing returns } \\
\text { positive or indeterminate) }\end{array}$} & \\
\hline $\begin{array}{l}\text { Low risk }^{d} \\
\text { (birth or residence or } \\
\text { long-term travele in } \\
\text { Australia, North Americag } \\
\text { or Western Europe) }\end{array}$ & \multicolumn{2}{|c|}{$\begin{array}{l}\text { Screening not generally required, no investigations required unless there is } \\
\text { clinical suspicion of hyperinfection }\end{array}$} & $\begin{array}{l}\text { Send serology } \text {, stool OAP, and sputum } \\
\text { OAP (+/- other bodily fluid or tissues for } \\
\text { examination for larvae) } \\
\text { Unlikely to require empiric ivermectin } \\
\text { therapy }\end{array}$ \\
\hline
\end{tabular}

Abbreviations: COVID-19, coronavirus disease 2019; ICU, intensive care unit; OAP, ova and parasites

Consult an infectious diseases / tropical medicine expert before administering ivermectin if patient is from a Loa loa endemic area

${ }^{b}$ Ivermectin weight-based doses should be rounded to the nearest whole tablet $(3 \mathrm{mg})$ size

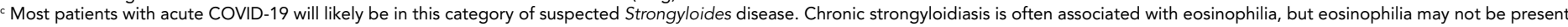
once the patient progresses to symptomatic or disseminated disease

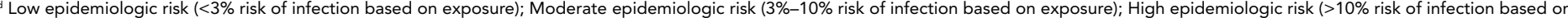

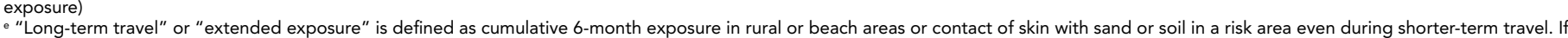
significant re-exposure accumulates, consider re-screening if initially negative

Areas of Central America outside of Mexico may be higher than moderate risk

9 Areas of North America that may be higher than low risk include Florida, Kentucky and Virginia. Aboriginal Australians are also at elevated risk of strongyloidiasis

${ }^{\mathrm{h}}$ Clinicians may consider a direct request to expedite Strongyloides serology testing (especially if a negative result will potentially avoid administration of an ivermectin dose) 